\title{
РЕЗУЛЬТАТЫ ИСПОЛЬЗОВАНИЯ СОВРЕМЕННЫХ СИСТЕМ УПРАВЛЕНИЯ СТАДОМ В МОЛОЧНОМ СКОТОВОДСТВЕ
}

\section{I.P. Ivanova, I.V. Trotsenko, V.V. Trotsenko \\ THE RESULTS OF USING MODERN STOCK MANAGEMENT SYSTEMS IN DAIRY CATTLE BREEDING}

Иванова Ирина Петровна - канд. с.-х. наук, доц. каф. зоотехнии Омского государственного аграрного университета им. П.А. Столыпина, г. Омск. E-mail: ip.ivanova@omgau.org

Троценко Ирина Викторовна - канд. с.-х. наук, доц. каф. зоотехнии Омского государственного аграрного университета им. П.А. Столыпина, г. Омск. E-mail: iv.trotsenko@omgau.org

Троценко Виктор Васильевич - кандидат технических наук, доц. каф. математических и естественнонаучных дисциплин Омского государственного аграрного университета им. П.А. Столыпина, г. Омск. E-mail: vv.trotsenko@omgau.org

Цель исследования - сравнение показателей молочного скотоводства до внедрения $в$ производство автоматизированных систем управления стадом и после. Основные задачи: анализ изменений в организации зоотехнического учета, воспроизводства поголовья и качественных характеристик произведенного молока. Исследование проводилось в Омской области в 10 сельскохозяйственных предприятиях, из которых 5 имеют статус племенных репродукторов, общее поголовье коров 6241 голов. Сравнительный анализ показателей молочного скотоводства представлен с 2000 по 2018 г. Выделено два периода: 1 период (2000-2009 гг.) - традиционная технология; 2 период (2010-2018 ге.) - технология с использованием элементов умной фермы. Удельный вес ошибок в зоотехническом учете при традиционной технологии производства молока находился на уровне 27 \% от общего поголовья. В период с 2000 до 2009 г. на долю ошибок по причине потери индивидуального номера приходилось $13 \%$, что на $4 \%$ больше,
Ivanova Irina Petrovna - Cand. Agr. Sci., Assoc. Prof., Chair of Zootechnics, Omsk State Agrarian university named after P.A. Stolypin, Omsk.

E-mail: ip .ivanova@omgau.org

Trotsenko Irina Victorovna - Cand. Agr. Sci., Assoc. Prof., Chair of Zootechnics, Omsk State Agrarian University named after P.A. Stolypin, Omsk. E-mail: iv.trotsenko@omgau.org

Trotsenko Victor Vasilyevich - Cand. Techn. Sci., Assoc. Prof., Chair of Mathematical and NaturalScience Disciplines, Omsk State Agrarian University named after P.A. Stolypin, Omsk.

E-mail: vv.trotsenko@omgau.org

чем по причине повторяющихся номеров в пределах одного предприятия. За период $c$ 2010 по 2018 г. произошло снижение удельного веса ошибок идентицрикации коров на 24 \% и сократилась кратность осеменения одной головы в среднем по исследуемым предприятиям до 2,3, а фоктическая яловость снизилась до $32,7 \%$. Анализ сортности произведенного молока по исследуемым предприятиям показал, что в период до 2010 г. доля молока высшего сорта в валовом производстве составляла 42 $\%$, а после ввода в эксплуатацию доильных залов удельный вес молока высшего сорта составил 56 \%, качество произведенного молока улучшилось на 14 \%. Таким образом, благодаря элементам умной фермы, удельный рост прибыли от реализации молока составил $+42 \%$, а 8 отдельных производственных условиях удельная прибыль увеличилась на $68 \%$.

Ключевые слова: системы управления стадом, иифровое животноводство, умная ферма. 
The aim of the study was to compare the indicators of dairy cattle breeding before the introduction of automated herd management systems into production and after. The main tasks were the analysis of changes in the organization of zootechnical accounting, reproduction of livestock and quality characteristics of produced milk. The study was conducted in Omsk Region in 10 agricultural enterprises, 5 of which have the status of breeding reproducers, the total number of cows - 6241 heads. A comparative analysis of dairy cattle indicators was presented from 2000 to 2018. Two periods were allocated: period 1 (2000-2009) - traditional technology; period 2 (2010-2018) - the technology with using smart farm elements. The share of errors in zootechnical accounting with traditional technology of milk production was at the level of $27 \%$ of the livestock. In the period from 2000 to 2009, the errors due to loss of individual numbers made 13 $\%$, which was $4 \%$ more than due to repeated numbers within the same enterprise. During the period from 2010 to 2018 there was a decrease in the proportion of errors in the identification of cows by $24 \%$ and the frequency of insemination of one head on average for studied enterprises reduced to 2.3, and the actual number of yeldness decreased by $32.7 \%$. The analysis of the grade of the milk produced by studied enterprises showed that in the period up to 2010, the share of high-grade milk in gross production was $42 \%$, and after commissioning of milking parlors, the proportion of high-grade milk was $56 \%$, the quality of milk produced improved by $14 \%$. Thus, thanks to the elements of a smart farm, specific profit growth from the sale of milk was $+42 \%$, and in some production conditions, the specific profit increased by $68 \%$.

Keywords: herd management systems, digital animal husbandry, smart farm.

Введение. Развитие цифрового животноводства в мире началось около тридцати лет назад, и в настоящее время современные технические решения сопоставимы с робототехникой, так как все технологические процессы выполняются без прямого участия человека.

В условиях Омской области молочное скотоводство достигло достаточного уровня разви- тия, и наряду с традиционными технологиями производства молока применяются современные цифровые технологии. Технический прогресс не стоит на месте и активно внедряется во все сферы деятельности человека, в том числе в молочное скотоводство. Основными причинами внедрения технических новшеств в сельское хозяйство являются сокращение затрат на производство продукции и получение максимальной прибыли $[1,3]$. Таким образом, анализ результатов использования современных автоматизированных технологий производства молока является актуальным для животноводства региона.

Цель исследования: определить эфффективность производства молока при внедрении современных автоматизированных систем управления стадом в условиях предприятий Омской области.

Объекты и методы исследования. Исследование проводилось в Институте ветеринарной медицины и биотехнологии Омского государственного аграрного университета.

Объектом исследования послужила современная автоматизированная технология производства молока в ведущих предприятиях Омской области. Для проведения исследования были выбраны предприятия, внедрившие в свое производство элементы умной фермы. При проведении исследования основные производственные показатели анализировались за два периода хозяйственной деятельности предприятий - до внедрения умной фермы и после. Анализ производственной деятельности предприятий проводился за период с 2000 по 2018 г. Автоматизированные системы управления стадом в Омской области стали использоваться с 2009 г. Таким образом, нами было выделено два периода: 1-й период - 2000-2009 гг. - традиционная технология производства молока; 2-й период - 2010-2018 гг. - технология производства молока с использованием элементов умной фермы.

Проведен анализ изменения показателей производства молока в зависимости от использования современных автоматизированных систем. Схема исследования представлена на рисунке. 


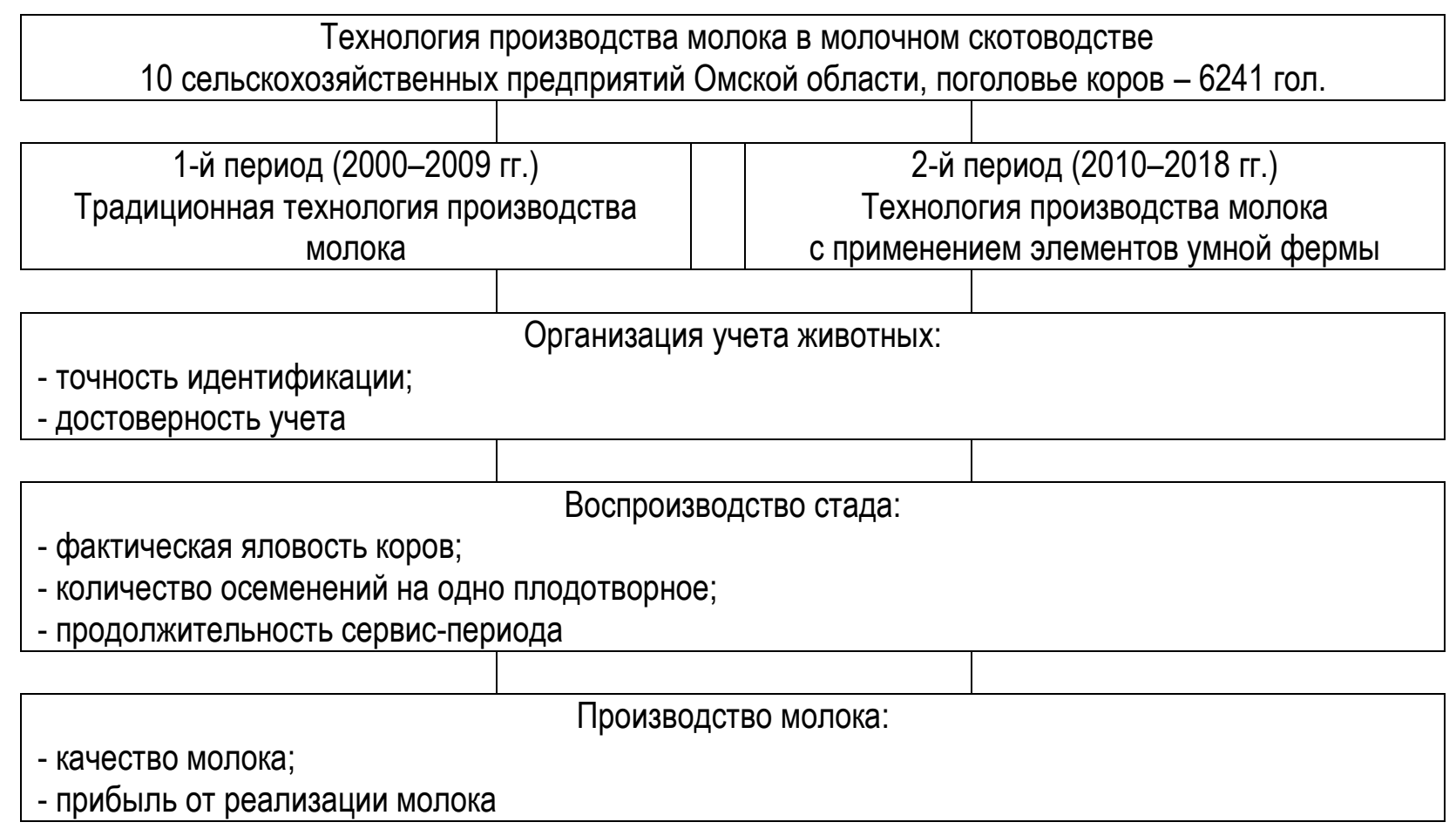

Схема исследований

Результаты исследования. Животноводческие предприятия Омской области имеют различный статус, поэтому формы ведения зоотехнического учета отличаются. Пять предприятий, вошедших в исследование, имеют статус племенных репродукторов, которые используют пакет программ «ИАС СЕЛЭКС молочный СКОТ». Товарные молочные комплексы используют разные пакеты программ, в большей степени подходящие для конкретных производственных условий, такие как Dataflow и DeliMaster. Программное обеспечение позволяет вести первичный и племенной зоотехнический учет $[2,7]$.

Для производства молока в предприятиях региона содержат коров красной степной и чернопестрой породы.

Приоритетным направлением в современном животноводстве является умное животноводство, которое в Западной Сибири только набирает свои обороты. 2016-2018 гг. были названы «годами испытаний», по результатам которых был спрогнозирован тренд увеличения «умных» систем, внедряемых в производство.

В молочном скотоводстве в настоящее время можно выделить три ключа к успеху - это достоверный учет, использование цифровых технологий и грамотный контроль и интерпретация полученных данных специалистом $[4,5]$.

В период с 2000 по 2009 г. идентификация животных в предприятиях Омской области обеспечивалась мечением молодняка, бирками, ошейниками, таврением. Данные о происхождении, развитии и продуктивности коров систематизировались механическим способом, а зоотехнический учет проводился с использованием картотеки коров, заполнялись другие установленные формы.

При внедрении автоматизированного учета с 2010 г. в исследуемых предприятиях для идентификации животных используется транспондер и две дублирующиеся ушные бирки. Для организации достоверного первичного и племенного зоотехнического учета важно избегать ошибок при идентификации животных.

Анализируя удельный вес ошибок при ведении зоотехнического учета, следует отметить, что при традиционной технологии производства молока он находился на уровне $27 \%$ от общего поголовья крупного рогатого скота. В период с 2000 до 2009 г. на долю ошибок по причине потери индивидуального номера приходилось $13 \%$, что на $4 \%$ больше, чем по причине повторяющихся номеров в пределах одного предприятия. Некорректная 
запись происхождения коров обусловлена отсутствием достоверной информации о предках коров. Нарушения в присвоении индивидуальных номеров животным в последующем искажали достоверность учета производственных показателей, тем самым затрудняя правильную организацию молочного скотоводства.

В результате внедрения электронной системы идентификации животных в условиях предприятий произошло изменение некоторых показателей производства, а также сократилось количество ошибок идентификации. Так, за период с 2010 по 2018 г. отмечается значительное сокращение ошибок при идентификации животных. Удельный вес выявленных ошибок составил $3 \%$ от общего поголовья коров, и не было выявлено нарушений в присвоении индивидуальных номеров. Потеря индивидуального номера животным также исключена. Кроме того, для повышения достоверности зоотехнического учета при вводе данных применяется календарь, международные справочники допустимых значений при вводе реквизитов: порода, вид животного, пол, заболевание, вакцина, результат исследований и т. д.

При автоматизированном учете выявлено $3 \%$ нарушений в записях происхождения коров. Эти ошибки вызваны различным написанием кличек быков-производителей зарубежной селекции, из-за транслитерации их кличек, так как в стране нет единой системы перевода кличек животных иностранного происхождения. За период с 2010 по 2018 г. произошло снижение удельного веса ошибок идентификации коров на $24 \%$.

Своевременное выявление коров в охоте и передача их на осеменение являются важнейшим технологическим звеном в производстве молока. В таблице 2 представлены показатели воспроизводства коров в предприятиях за период с 2000 по 2018 г.

\section{Воспроизводительные качества коров}

Таблица 2

\begin{tabular}{|l|c|c|}
\hline \multicolumn{1}{|c|}{ Показатель } & 1 -й период & 2 -й период \\
\hline Количество осеменений на одно плодотворное, доз & $4,1 \pm 0,7$ & $2,3 \pm 0,5$ \\
\hline Фактическая яловость, \% & $44,2 \pm 2,8$ & $32,7 \pm 1,3$ \\
\hline Продолжительность сервис-периода, дн. & $183 \pm 12,4$ & $156 \pm 7,2$ \\
\hline
\end{tabular}

Анализ показателей воспроизводства стада коров в исследуемых предприятиях показал значительную положительную динамику после внедрения умной фермы. В среднем по предприятиям Омской области до внедрения элементов умной фермы и автоматизированной системы выявления коров в охоте количество осеменений на одно плодотворное составляло 4,1 раза, что затрудняло организацию воспроизводства молочного скота. За период с 2010 по 2018 г. произошло сокращение кратности осеменения одной головы в среднем по исследуемым предприятиям до 2,3.
Таким образом, благодаря автоматизированной системе контроля за воспроизводством, в предприятиях Омской области удалось сократить фактическую яловость до 32,7 \%.

В настоящее время предприятиям экономически выгоднее производить молоко высшего качества. Улучшить качественные характеристики произведенного молока возможно только модернизировав доильное оборудование [6]. Физико-химические показатели молока являются основными критериями для определения его сортности. Средние значения показателей качества молока представлены в таблице 3.

Таблица 3

\section{Физико-химическая характеристика молока}

\begin{tabular}{|c|c|c|}
\hline Показатель & 1-й период & 2-й период \\
\hline Кислотность, ${ }^{\circ} \mathrm{T}$ & $17,6 \pm 3,21$ & $17,2 \pm 0,15$ \\
\hline Группа чистоты & $1 \ldots 2$ & 1 \\
\hline Плотность, кг/M & $1027 \pm 2,4$ & $1028 \pm 2,1$ \\
\hline Массовая доля истинного белка, \% & $2,7 \pm 0,04$ & $2,8 \pm 0,03$ \\
\hline
\end{tabular}


Анализируя полученные данные, можно заключить, что за 2-й период произошли изменения физико-химических показателей молока по региону. Улучшилась группа чистоты получаемого молока в условиях модернизированных ферм. Все получаемое молоко в современных автоматизированных доильных залах относится к первой группе чистоты, что, несомненно, обусловлено оптимизацией технологии доения и

минимальным контактом молока-сырья с окружающей средой.

Анализ валового производства молока в зависимости от сортности представлен в таблице 4 .

В период до 2010 г. доля молока высшего сорта в валовом производстве составляла $42 \%$, а после ввода в эксплуатацию доильных залов удельный вес молока высшего сорта составил $56 \%$, качество произведенного молока улучшилось на $14 \%$.

Таблица 4

Произведено молока, \%

\begin{tabular}{|l|c|c|}
\hline \multicolumn{1}{|c|}{ Сорт молока } & 1-й период & 2 -й период \\
\hline Высший & $42 \pm 4,8$ & $56 \pm 4,1$ \\
\hline Первый & $36 \pm 4,2$ & $31 \pm 3,8$ \\
\hline Второй & $22 \pm 3,3$ & $13 \pm 3,6$ \\
\hline
\end{tabular}

Анализ экономической эфффективности использования современных систем управления стадом в условиях Омской области свидетельствует о целесообразности модернизации молочного скотоводства региона. В настоящее время рентабельность производства молока в исследуемых предприятиях относительно низкая, так как стоимость оборудования умной фрермы достаточно высокая и окупается в течение длительного времени. Поэтому основным показателем эфффективности можно считать удельный объем выручки от реализации молока до внедрения современных технологий и после с учетом цены реализации молока.

Удельный рост прибыли от реализации произведенного молока в условиях предприятий региона составил $+42 \%$, а в отдельных производственных условиях удельная прибыль увеличилась на $68 \%$.

Выводы. Улучшение труда и совершенствование технологии за счет применения современного оборудования создают предпосылки для увеличения продуктивности животных. В результате работы умной фермы отмечено сокращение затрат на плодотворное осеменение до 52,3 \% в результате сокращения кратности осеменения коров, увеличение выхода молодняка из-за снижения яловости на 34 \%. Благодаря улучшению качественных показателей молока и снижению трудозатрат использование современных технологий способствовало увеличению удельной прибыли от реализации произведенного молока на 42-68 \%.

\section{Литература}

1. Артемова Е.И., Шпак Н.М. Цифровизация как инструмент инновационного развития молочного скотоводства // Вестн. Академии знаний. - 2019. - № 2 (31). - С. 15-19.

2. Бурда А.Г., Бурда С.А. Целесообразность применения электронной системы управления молочным стадом в условиях циф-ровизации экономики // Научный вестник Южного института менеджмента. - 2018. № 3 (23). - C. 38-43.

3. Кудрин М.Р., Ижболдина С.Н., Новых Н.Н. Организация экономически эффрективного производства молока на основе современных технологий // Вестн. Ижевской государственной сельскохозяйственной академии. 2014. - № 2 (39). - С. 8-11.

4. Михальский А.И., Новосельцева Ж.А. Методы компьютерного анализа данных в задачах по мониторингу и совершенствованию управления стадом // Проблемы биологии продуктивных животных. - 2019. № 1. - С. 95-111.

5. Спешилова И.В. Развитие отрасли молочного скотоводства в инновационных условиях цифровизации экономики РФ // Научное обозрение: теория и практика. - 2019. Т. 9, № 7 (63). - С. 961-969.

6. Троценко И.В., Иванова И.П. Характеристика качества молока - сырья для производ- 
ства молочных продуктов // Современное состояние, перспективы развития молочного животноводства и переработки сельскохозяйственной продукции: мат-лы междунар. науч.-практ. конф. (7-8 апреля 2016, Омск) / Омский гос. аграр. ун-т. - Омск: ЛИTEPA, 2016. - C. 367-369.

7. Цой Ю.А., Баишева Р.А. Система управления стадом на молочной ферме // Инновации в сельском хозяйстве. - 2018. - № 3 (28). - C. 612-617.

\section{Literatura}

1. Artemova E.I., SHpak N.M. Cifrovizaciya kak instrument innovacionnogo razvitiya molochnogo skotovodstva // Vestn. Akademii znanij. - 2019. - № 2 (31). - S. 15-19.

2. Burda A.G., Burda S.A. Celesoobraznost' primeneniya elektronnoj sistemy upravleniya molochnym stadom $v$ usloviyah cifrovizacii ekonomiki // Nauchnyj vestnik YUzhnogo instituta menedzhmenta. - 2018. - № 3 (23). S. 38-43.

3. Kudrin M.R., Izhboldina S.N., Novyh N.N. Organizaciya ekonomicheski effektivnogo proizvodstva moloka na osnove sovremennyh tekhnologij // Vestn. Izhevskoj gosudarstvennoj sel'skohozyajstvennoj akademii. 2014. - № 2 (39). - S. 8-11.

4. Mihal'skij A.I., Novosel'ceva ZH.A. Metody komp'yuternogo analiza dannyh $\mathrm{v}$ zadachah po monitoringu i sovershenstvovaniyu upravleniya stadom // Problemy biologii produktivnyh zhivotnyh. - 2019. - № 1. S. 95-111.

5. Speshilova I.V. Razvitie otrasli molochnogo skotovodstva $v$ innovacionnyh usloviyah cifrovizacii ekonomiki RF // Nauchnoe obozrenie: teoriya i praktika. - 2019. - T. 9 , № 7 (63). - S. 961-969.

6. Trocenko I.V., Ivanova I.P. Harakteristika kachestva moloka - syr'ya dlya proizvodstva molochnyh produktov // Sovremennoe sostoyanie, perspektivy razvitiya molochnogo zhivotnovodstva i pererabotki sel'skohozyajstvennoj produkcii: mat-ly mezhdunar. nauch.-prakt. konf. (7-8 aprelya 2016, Omsk) I Omskij gos. agrar. un-t. - Omsk: LITERA, 2016. - S. 367-369.

7. Coj Yu.A., Baisheva R.A. Sistema upravleniya stadom na molochnoj ferme // Innovacii v sel'skom hozyajstve. - 2018. - № 3 (28). S. 612-617. 